\title{
The Relationships among Perception of Body Image, a Desire for Thinness, and Dieting Behavior in Young Females in Japan
}

\author{
Tomoki Mase', Chiemi Miyawaki², Kumiko Ohara ${ }^{3,4}$, Harunobu Nakamura ${ }^{3 *}$ \\ ${ }^{1}$ Department of Childhood Education, Kyoto Seibo College, Kyoto, Japan \\ ${ }^{2}$ Department of Early Childhood Education, Heian Jogakuin (St. Agnes') College, Kyoto, Japan \\ ${ }^{3}$ Graduate School of Human Development and Environment, Kobe University, Kobe, Japan \\ ${ }^{4}$ Research Fellow of Japan Society for the Promotion of Science, Tokyo, Japan \\ Email: ${ }^{*}$ hal@kobe-u.ac.jp
}

Received 22 December 2014; accepted 5 January 2015; published 19 January 2015

Copyright (C) 2015 by authors and Scientific Research Publishing Inc.

This work is licensed under the Creative Commons Attribution International License (CC BY). http://creativecommons.org/licenses/by/4.0/

(c) (i) Open Access

\section{Abstract}

The aim of this study was to investigate the relationship among body image perceptions, a desire for thinness, and dieting behavior in young females in Japan. The subjects were 302 Japanese female university students (age $19.9 \pm 1.4$ years). An anonymous, self-administered questionnaire survey was conducted between July and August 2011. The questionnaire clarified the subjects' physical status, perception about personal body shape, desired body shape, the time frame when they first thought about body shape dieting, exercise habits, and eating behaviors. The results revealed that many of the underweight or normal weight subjects perceived themselves as obese, and often the reasons for the perception of obesity were comparisons with others or with themselves in the past. The scores of EAT-26 in those who perceived themselves as obese were higher than the scores in those who did not. Those who perceived themselves as obese had a desire to become slim, were concerned about body shape at an early age, were concerned about dieting, had dieting experience, and were willing to increase daily exercise. These results indicated that incorrect perceptions about body shape have connection to a desire for thinness and dieting behavior.

\section{Keywords}

Female Students, Perception of Body Shape, Dieting, Eating Behavior, Desire for Thinness

\footnotetext{
${ }^{*}$ Corresponding author.
} 


\section{Introduction}

Undernutrition can cause various physical disorders, such as anemia, menstrual disorders, or osteoporosis [1]-[3]. Being underweight (body mass index $<18.5$ ) is partly related with undernutrition [4]. However, the number of underweight people has been increasing, particularly among the females in twenties in Japan, from $24.2 \%$ in 2000 [5] to $29.0 \%$ in 2010 [6]. Therefore, the increase in underweight people has become an important health problem among young females. Thus, the Japanese government has established a goal to decrease the proportion of underweight females to $20 \%$ by 2022 during the second term of National Health Promotion Movement of the twenty-first century [Health Japan 21 (the second term)] [7].

On the other hand, many young females, including underweight or normal weight females, have a desire for thinness [8] [9]. Moreover, underweight or normal weight females often have a mistaken perception of their own body image. Indeed, more than half of young females think they are fat, although they are not actually fat [8] [10]. This tendency was also found during the younger teen years in females [11]-[13].

From these previous results, those who have incorrect perceptions about body image and those who have a desire for thinness may display certain dieting behaviors to lose weight. It has been reported that most Japanese girls overestimated their body weights, were dissatisfied with their body shape, and wanted to lose weight [14]. The association between a desire for thinness and dieting behavior has been investigated by Ikeda et al., but definite conclusions could not be drawn [8]. Therefore, in the present study, we investigated the relationship among the perception of body image, a desire for thinness, and dieting behaviors in young females in Japan.

\section{Methods}

\subsection{Subjects}

The subjects were 302 Japanese female university students (age $19.9 \pm 1.4$ years). An anonymous, self-administered questionnaire survey was conducted between July and August2011. The questionnaire forms were delivered in the class, and the collection rate was $100 \%$, and the valid response rate was $91.1 \%(\mathrm{n}=275)$. The subjects were classified into three groups according to the World Health Organization (WHO) criteria: overweight (BMI $\geq 25.0 \mathrm{~kg} / \mathrm{m}^{2}, \mathrm{n}=7$ ), normal weight $\left(18.5 \leq \mathrm{BMI}<25 \mathrm{~kg} / \mathrm{m}^{2}, \mathrm{n}=214\right)$, and underweight (BMI $<18.5$ $\mathrm{kg} / \mathrm{m}^{2}, \mathrm{n}=54$ ). All subjects provided informed consent, and the study received the approval of the Human Ethics Committee of the Graduate School of Human Development and Environment, Kobe University.

\subsection{Questionnaire}

The questionnaire clarified the subjects' physical status, perception of personal body shape, desired body shape, period of concerning with body shape, dieting, exercise habits, and eating behaviors. Physical status included four items: age, height, weight, and ideal weight. Body mass index (BMI) $\left(\mathrm{kg} / \mathrm{m}^{2}\right)$ was calculated as weight in kilograms divided by the square of height in meters. Ideal BMI was similarly calculated, using the ideal weight and height. The responses for "perception of body shape" included "slim", "a little slim", "normal”, "a little obese", and "obese". We combined "slim" and "a little slim" into the "slim" classification, and "obese" and "a little obese" into the "obese" classification for the analysis. Those who responded "obese" or "a little obese" were also asked the reason why they saw themselves as obese, and the responses included "comparison with themselves in the past", "based on current body weight or body fat", and "comparison with others" [15]. The responses for "desired body shape" included "become fat", "maintain the current shape", or "become thin". We also asked participants who responded "become thin" about their reasons for desiring to be thin ("for health" or "for beauty"). The responses for "period of concerning with body shape" included "in elementary school," "in junior high school”, "in high school”, "in university”, and "not concerned”. Questions about dieting pertained to "concerns with dieting", "dieting experience", and "period when first started dieting". The responses for "concerns with dieting" and "experience with dieting" included "yes" or "no". We also asked participants who responded "yes" to "experience with dieting" about their main method of dieting ("exercise," "skip meals," "reduce meals", or "skip snacks"). Then, we categorized "skip meals," "reduce meals," and "skip snacks" into the one group named "diet restriction" for the analysis. The responses for "period when first started dieting" included "in elementary school", "in junior high school", "in high school", or "in university". Exercise habits included questions pertaining to "current exercise habits", "lack of exercise", and "a will to increase daily exercise”. The responses for "current exercise habits" included "seldom”, “a few times per month”, “a few times per 
week", or "usually". We categorized "a few times per week" and "usually” into "habitual” and "seldom” and "a few times per month" into "not habitual" for the analysis. The responses for "lack of exercise" included "yes" or "no." The responses for "a will to increase daily exercise" included "try to increase" or "do not try to increase".

Eating behavior was assessed by the Japanese version of the Eating Attitude Test 26 (EAT-26) [16]. EAT-26 is a 26-item self-rated questionnaire, and is divided into three subscales: Dieting (13 items), Bulimia and Food preoccupation (6 items), and Oral control scale (7 items) [17]. The items are rated on a six-point Likert scale: "never”, "rarely", "sometimes", "often”, "usually”, and "always”. Responses were quantified by assigning a score of 0 for "never”, "rarely”, or "sometimes", 1 for "often”, 2 for "usually”, and 3 for "always", according to an original article by Garner et al. [17]. Subjects with a total EAT-26 score that was equal to or greater than 20 were designated as seriously disturbed.

\subsection{Analysis}

The Student t-test was used to evaluate the difference between two groups. The chi square test was used to test the response rate in cross-tabulation. The statistical level for significance was set at 0.05 . Statistical analysis was performed by SPSS ${ }^{\circledR} 15.0 \mathrm{~J}$ for Windows (SPSS Inc., Chicago, USA).

\section{Results}

The means of height, body weight, and BMI of the participants were $157.6 \pm 5.3 \mathrm{~cm}, 50.4 \pm 6.0 \mathrm{~kg}$, and $20.3 \pm$ 2.1, respectively (Table 1). According to the classification of body shape by BMI, underweight subjects made up $19.6 \%(n=54)$ of the study population, normal weight subjects accounted for $77.8 \%(n=214)$, and overweight subjects accounted for $2.5 \%(n=7)$.

Among the underweight and normal weight subjects, 59.3\% $(\mathrm{n}=159)$ answered that they were obese or a little obese $(5.2 \%$, underweight; $54.1 \%$, normal weight), and $40.7 \%(n=109)$ answered that they were normal, a little slim, or slim (14.9\%, underweight; $25.7 \%$, normal weight). Regarding the reason why they thought they were obese, $30.6 \%(n=48)$ answered "comparison with themselves in the past", 52.2\% $(n=82)$ answered "comparison with others", and 17.2\% $(n=27)$ answered "based on current body weight or body fat".

Body weight, BMI, and ideal BMI were significantly higher in the "perceived themselves as obese" group than in the "perceived themselves as not obese" group ( $<<0.001$ for body weight and BMI, $\mathrm{p}=0.003$ for ideal BMI) (Table 2).

Those who perceived themselves as obese had a desire to become slim $(\mathrm{p}<0.001)$, were more concerned with body shape in early stage $(\mathrm{p}<0.001)$, were more concerned with dieting $(\mathrm{p}<0.001)$, had more dieting experience ( $\mathrm{p}<0.001)$, and had a will to increase daily exercise $(\mathrm{p}=0.046)$, when compared with those who did not perceive themselves as obese (Table 3 ).

The averages and standard deviations of the total EAT-26 scores for all participants were $5.5 \pm 6.2$. The total EAT-26 scores of subjects who perceived themselves as obese were significantly higher than those of subjects who did not perceive themselves as obese (Table 4). A comparison of factor scores showed that the score for the first factor (dieting) and the second factor (bulimia and food preoccupation) in those who perceived themselves as obese were significantly higher than those in the participants who did not perceive themselves as obese. In addition, in those who perceived themselves as obese, the total EAT-26 score and the first factor score were significantly higher in underweight subjects than those in normal weight subjects (Table 5).

Table 1. Physical characteristics of the subjects.

\begin{tabular}{cc}
\hline & Mean and standard deviations $(\mathrm{n}=275)$ \\
\hline Age (years) & $19.9 \pm 1.4(18.0-23.0)$ \\
Height $(\mathrm{cm})$ & $157.6 \pm 5.3(142.6-171.0)$ \\
Body weight $(\mathrm{kg})$ & $50.4 \pm 6.0(36.0-76.0)$ \\
BMI $\left(\mathrm{kg} / \mathrm{m}^{2}\right)$ & $20.3 \pm 2.1(16.0-31.2)$ \\
\hline
\end{tabular}

( ): Range of value; BMI: Body mass index. 
Table 2. Comparisons of physical characteristics of the different groups.

\begin{tabular}{cccc}
\hline & $\begin{array}{c}\text { Perceived as obese } \\
(\mathrm{n}=159)\end{array}$ & $\begin{array}{c}\text { Perceived as not obese } \\
(\mathrm{n}=109)\end{array}$ & p-value \\
\hline Height $(\mathrm{cm})$ & $157.2 \pm 5.3$ & $158.2 \pm 5.3$ & 0.163 \\
Body weight $(\mathrm{kg})$ & $51.4 \pm 5.1$ & $47.6 \pm 4.5$ & $<0.001$ \\
BMI $\left(\mathrm{kg} / \mathrm{m}^{2}\right)$ & $20.8 \pm 1.7$ & $19.0 \pm 1.3$ & $<0.001$ \\
Ideal body weight $(\mathrm{kg})$ & $46.0 \pm 3.9$ & $45.3 \pm 3.8$ & 0.160 \\
Ideal BMI $\left(\mathrm{kg} / \mathrm{m}^{2}\right)$ & $18.6 \pm 1.3$ & $18.1 \pm 1.2$ & 0.003 \\
\hline
\end{tabular}

Values are means \pm standard deviations; BMI: Body mass Index; Differences in mean values between "perceived as obese" group and "perceived as not obese" group were assessed with student's t test comparison procedure.

Table 3. Relationships among perceptions for the study groups.

\begin{tabular}{|c|c|c|c|c|}
\hline & $\begin{array}{l}\text { Perceived as } \\
\text { obese \% (n) }\end{array}$ & $\begin{array}{l}\text { Perceived as not } \\
\text { obese \% (n) }\end{array}$ & $\begin{array}{l}\text { Total } \\
\%(n)\end{array}$ & $\mathrm{p}$-value \\
\hline \multicolumn{5}{|l|}{ Desire for body shape } \\
\hline Become fat & $0(0)$ & $6.5(7)$ & $2.6(7)$ & \multirow{3}{*}{$<0.001$} \\
\hline Maintain the current shape & $3.2(5)$ & $38.3(41)$ & $17.4(46)$ & \\
\hline Become slim & $96.8(153)$ & $55.1(59)$ & $80.0(212)$ & \\
\hline \multicolumn{5}{|l|}{ Reason of weight loss } \\
\hline For health & $15.4(23)$ & $6.9(4)$ & $13.0(27)$ & \multirow[t]{2}{*}{0.075} \\
\hline For beauty & $84.6(126)$ & $93.1(54)$ & $87.0(180)$ & \\
\hline \multicolumn{5}{|l|}{ Period of concerning with body } \\
\hline In elementary school & $19.5(31)$ & $12.8(14)$ & $16.8(45)$ & \multirow{5}{*}{$<0.001$} \\
\hline In junior high school & $30.8(49)$ & $30.3(33)$ & $30.6(82)$ & \\
\hline In high school & $44.0(70)$ & $32.1(35)$ & $39.2(105)$ & \\
\hline In university & $5.7(9)$ & $11.9(13)$ & $8.2(22)$ & \\
\hline None & $0(0)$ & $12.8(14)$ & $5.2(14)$ & \\
\hline \multicolumn{5}{|l|}{ Concern with dieting } \\
\hline Yes & $95.6(151)$ & $64.2(70)$ & $82.8(221)$ & \multirow[t]{2}{*}{$<0.001$} \\
\hline No & $4.4(7)$ & 35.8 (39) & $17.2(46)$ & \\
\hline \multicolumn{5}{|l|}{ Dieting experiences } \\
\hline Yes & $87.3(138)$ & $63.0(68)$ & $77.4(206)$ & \multirow[t]{2}{*}{$<0.001$} \\
\hline No & $12.7(20)$ & $37.0(40)$ & $22.6(60)$ & \\
\hline \multicolumn{5}{|l|}{ Main method of dieting } \\
\hline Exercise & $19.8(25)$ & $29.5(18)$ & $23.0(43)$ & \multirow{2}{*}{0.100} \\
\hline Diet restriction & $80.2(101)$ & $70.5(43)$ & $77.0(144)$ & \\
\hline \multicolumn{5}{|l|}{ Period to start dieting first } \\
\hline In elementary school & $4.4(6)$ & $2.9(2)$ & $3.9(8)$ & \multirow{4}{*}{0.604} \\
\hline In junior high school & $25.0(34)$ & $29.4(20)$ & $26.5(54)$ & \\
\hline In high school & $55.1(75)$ & $47.1(32)$ & 52.5 (107) & \\
\hline In university & $15.4(21)$ & $20.6(14)$ & $17.2(35)$ & \\
\hline \multicolumn{5}{|l|}{ Current exercise habits } \\
\hline Habitual & $12.6(20)$ & $14.7(16)$ & $13.4(36)$ & \multirow[t]{2}{*}{0.374} \\
\hline Not habitual & $87.4(139)$ & $85.3(93)$ & $86.6(232)$ & \\
\hline \multicolumn{5}{|l|}{ Feeling lack of exercise } \\
\hline Lack of exercise & $95.6(151)$ & 90.8 (99) & $93.6(250)$ & \multirow{2}{*}{0.097} \\
\hline Not lack of exercise & $4.4(7)$ & $9.2(10)$ & $6.4(17)$ & \\
\hline \multicolumn{5}{|l|}{ Will to increase daily exercise } \\
\hline Try to increase & $53.5(85)$ & $42.2(46)$ & $51.1(137)$ & \multirow[t]{2}{*}{0.046} \\
\hline Do not try to increase & 46.5 (74) & $57.8(63)$ & $48.9(131)$ & \\
\hline
\end{tabular}

Chi-square test was used for the test of response rate in cross tabulation. 
Table 4. EAT-26 and factor scores of the different groups.

\begin{tabular}{cccc}
\hline & $\begin{array}{c}\text { Perceived as obese } \\
(\mathrm{n}=159)\end{array}$ & $\begin{array}{c}\text { Perceived as not obese } \\
(\mathrm{n}=109)\end{array}$ & p-value \\
\hline EAT-26 Total score & $6.9 \pm 6.8$ & $3.6 \pm 4.8$ & $<0.001$ \\
Dieting (factor I) & $4.8 \pm 5.0$ & $1.9 \pm 3.3$ & $<0.001$ \\
Bulimia and food preoccupation (factor II) & $0.9 \pm 2.0$ & $0.4 \pm 1.0$ & 0.012 \\
Oral control (factor III) & $1.4 \pm 1.7$ & $1.4 \pm 2.1$ & 0.867 \\
\hline
\end{tabular}

Values are means \pm standard deviations; Differences in mean values were assessed with Student $t$ test comparison procedure.

Table 5. EAT-26 and factor scores of the participants in the obesity consciousness group.

\begin{tabular}{cccc}
\hline & $\begin{array}{c}\text { Underweight group } \\
(\mathrm{n}=14)\end{array}$ & $\begin{array}{c}\text { Normal weight group } \\
(\mathrm{n}=145)\end{array}$ & p-value \\
\hline EAT-26 Total score & $12.7 \pm 9.8$ & $6.3 \pm 6.2$ & 0.038 \\
Dieting (factor I) & $9.4 \pm 7.9$ & $4.4 \pm 4.4$ & 0.033 \\
Bulimia and food preoccupation (factor II) & $1.9 \pm 3.4$ & $0.8 \pm 1.8$ & 0.258 \\
Oral control (factor III) & $2.5 \pm 2.3$ & $1.3 \pm 1.6$ & 0.075 \\
\hline
\end{tabular}

Values are means \pm standard deviations; Differences in mean values were assessed with Student $t$ test comparison procedure.

\section{Discussion}

The present study investigated the relationship among the perception of body image, a desire for thinness, and dieting behavior in young females in Japan.

The main findings demonstrated that 1) many underweight or normal weight subjects perceived themselves as obese and the reason for that perception was the comparison with others or themselves in the past, 2) the scores of EAT-26 in participants who perceived themselves as obese were higher than the scores in those who perceived themselves as not obese, 3 ) those who perceived themselves as obese had a desire to become slim, were concerned with body shape at an early stage, were concerned with dieting, had dieting experience, and had a will to increase daily exercise.

In the present study, although the subjects were underweight or normal weight, about $60 \%$ of them thought that they were obese. Ikeda et al. reported that $66.4 \%$ of female students had incorrect perceptions about their body shapes [8], which was consistent with the present results. In addition, the present results showed that the reasons that they perceived themselves as obese were mainly comparisons with themselves in the past or comparisons with others, and was not based on body weight or fat percentage. In addition, the mean BMI in those who perceived themselves as obese was larger than that in those who perceived themselves as not obese. These results indicated that the young women evaluated their body shapes from relative and not absolute information, which may misinform them about the perceptions of their body shapes.

In the present study, the wrong perception for body shape was related with a desire for thinness. This was consistent with previous results [8] [18]-[21]. In addition, in the present study, a wrong perception about body shape was associated with a concern with dieting and dieting experience. Similarly, previous studies had shown that many females were concerned with and had experienced dieting [8] [21]. However, the main method of dieting was not increasing the amount of exercise but through diet restriction, although the present subjects had a will to try to increase their exercise levels. Previous studies had also shown that exercise was not the main mechanism for dieting [9] [21]. The reason for the present result appears unclear. The scores of EAT-26 in those who perceived themselves as obese in the present study were high compared with those who did not perceive themselves as obese. From our findings, those who perceived themselves as obese had a stronger concern about eating behaviors than about physical activity. A more detailed investigation should be conducted in the future.

Some limitations of this study should be noted. First, its cross-sectional design precluded drawing conclusions 
about any kind of cause-effect relationship. Second, the samples were collected from a limited area in Japan. In addition, a minimum sample size was not calculated before sampling. Third, the questionnaire about the reason why subjects saw themselves as obese and the questionnaire about the methods of dieting in the present study have not been sufficiently validated. On the other hand, the strength of the present study was to investigate and clarify the relationship among the perception of body image, a desire for thinness, and dieting behaviors in young females.

\section{Conclusion}

The present study investigated the relationship among the perception of body image, a desire for thinness, and dieting behaviors in young females in Japan. Many of the underweight or normal weight subjects perceived themselves as obese, and the reasons for this perception were comparisons with others or themselves in the past. The scores of EAT-26 in participants who perceived themselves as obese were higher than those in participants who did not perceive themselves as obese. Those who perceived themselves as obese had a desire to become slim, were concerned with body shape at an early stage, were concerned with dieting, had dieting experience, and had a will to increase daily exercise. These results indicate that incorrect perceptions about body shape are associated with a desire for thinness and dieting behaviors.

\section{Acknowledgements}

The authors thank the participants of the present study.

\section{References}

[1] Selzer, R., Caust, J., Hibbert, M., Bowes, G. and Patton, G. (1996) The Association between Secondary Amenorrhea and Common Eating Disordered Weight Control Practices in an Adolescent Population. Journal of Adolescent Health, 19, 56-61. http://dx.doi.org/10.1016/1054-139X(95)00229-L

[2] Slupik, R.I. (1999) Managing Adolescents with Eating Disorders. International Journal of Fertility and Women's Medicine, 44, 125-130.

[3] Grinspoon, S., Thomas, E., Pitts, S., Gross, E., Mickley, D., Miller, K., Herzog, D. and Klibanski, A. (2000) Prevalence and Predictive Factors for Regional Osteopenia in Women with Anorexia Nervosa. Annals of Internal Medicine, 133, 790-794. http://dx.doi.org/10.7326/0003-4819-133-10-200011210-00011

[4] Ey Chua, E.Y., Zalilah, M.S., Ys Chin, Y.S. and Norhasmah, S. (2012) Dietary Diversity Is Associated with Nutritional Status of Orang Asli Children in Krau Wildlife Reserve, Pahang. Malaysian Journal of Nutrition, 18, 1-13.

[5] Ministry of Health, Labour and Welfare. Results of Year 2000 National Nutrition Survey. (In Japanese) http://www.mhlw.go.jp/toukei/kouhyo/indexkk_14_7.html

[6] Ministry of Health, Labour and Welfare (2012) Results of Year 2010 National Health and Nutrition Survey. (In Japanese) http://www.mhlw.go.jp/stf/houdou/2r98520000020qbb.html

[7] Ministry of Health, Labour and Welfare (2013) Health Japan 21. 2nd Edition. (In Japanese) http://www.mhlw.go.jp/bunya/kenkou/kenkounippon21.html

[8] Ikeda, J., Fukuda, S., Murakami, T. and Kawamoto, N. (2008) Desire for Slenderness in Adolescent Women: Transition during 14 Years in Dietetic Students of a Junior College. Nihon Koshu Eisei Zasshi, 55, 777-785. (In Japanese with English Abstract)

[9] Mase, T., Miyawaki, C., Kouda, K., Fujita, Y., Ohara, K. and Nakamura, H. (2013) Relationship of a Desire of Thinness and Eating Behavior among Japanese Underweight Female Students. Eating and Weight Disorders: EWD, 18, 125-132. http://dx.doi.org/10.1007/s40519-013-0019-x

[10] Ministry of Health, Labour and Welfare (2009) Results of Year 2008 National Health and Nutrition Survey. (In Japanese) http://www.mhlw.go.jp/houdou/2009/11/h1109-1.html

[11] Evans, E.H., Tovée, M.J., Boothroyd, L.G. and Drewett, R.F. (2013) Body Dissatisfaction and Disordered Eating Attitudes in 7- to 11-Year-Old Girls: Testing a Sociocultural Model. Body Image, 10, 8-15. http://dx.doi.org/10.1016/j.bodyim.2012.10.001

[12] Kaneko, K., Kiriike, N., Ikenaga, K., Miyawaki, D. and Yamagami, S. (1999) Weight and Shape Concerns and Dieting Behaviors among Pre-Adolescents and Adolescents in Japan. Psychiatry and Clinical Neurosciences, 53, 365-371. http://dx.doi.org/10.1046/j.1440-1819.1999.00559.x

[13] Rohde, P., Stice, E. and Marti, C.N. (2014) Development and Predictive Effects of Eating Disorder Risk Factors during 
Adolescence: Implications for Prevention Efforts. International Journal of Eating Disorders, Article First Published Online: 6 March 2014. http://dx.doi.org/10.1002/eat.22270

[14] Sano, A., Le, D.S., Tran, M.H., Pham, H.T., Kaneda, M., Murai, E., Kamiyama, H., Oota, Y. and Yamamoto, S. (2008) Study on Factors of Body Image in Japanese and Vietnamese Adolescents. Journal of Nutritional Science and Vitaminology, 54, 169-175. http://dx.doi.org/10.3177/jnsv.54.169

[15] Mase, T., Miyawaki, C., Kouda, K., Fujita, Y., Okita, Y., Ohara, K., Mimasa, F. and Nakamura, H. (2012) Association between Normal Weight Obesity and Diet Behaviors in Female Students. Nihon Koshu Eisei Zasshi, 59, 371-380.

[16] Kiriike, N. and Nagata, T. (1992) Self-Report Inventories in Eating Disorders. Archives of Psychiatric Diagnostics and Clinical Evaluation, 3, 457-464.

[17] Garner, D.M., Olmsted, M.P., Bohr, Y. and Garfinkel, P.E. (1982) The Eating Attitudes Test: Psychometric Features and Clinical Correlates. Psychological Medicine, 12, 871-878. http://dx.doi.org/10.1017/S0033291700049163

[18] Nishizawa, Y., Kida, K., Nishizawa, K., Hashiba, S., Saito, K. and Mita, R. (2003) Perception of Self-Physique and Eating Behavior of High School Students in Japan. Psychiatry and Clinical Neurosciences, 57, 189-196. http://dx.doi.org/10.1046/j.1440-1819.2003.01100.x

[19] Hayashi, F., Takimoto, H., Yoshita, K. and Yoshiike, N. (2006) Perceived Body Size and Desire for Thinness of Young Japanese Women: A Population-Based Survey. The British Journal of Nutrition, 96, 1154-1162. http://dx.doi.org/10.1017/BJN20061921

[20] Weinshenker, N. (2002) Adolescence and Body Image. School Nurse News, 19, 12-16.

[21] Shiraishi, T. (1999) Female University Students’ Desire for Thinness and Their Knowledge of Losing Weight. Adolescentology, 17, 460-465. (In Japanese with English Abstract) 
Scientific Research Publishing (SCIRP) is one of the largest Open Access journal publishers. It is currently publishing more than 200 open access, online, peer-reviewed journals covering a wide range of academic disciplines. SCIRP serves the worldwide academic communities and contributes to the progress and application of science with its publication.

Other selected journals from SCIRP are listed as below. Submit your manuscript to us via either submit@scirp.org or Online Submission Portal.
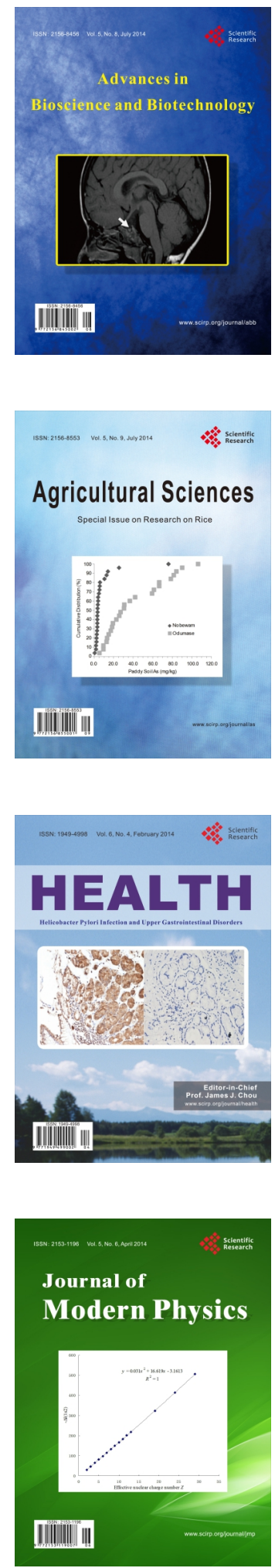
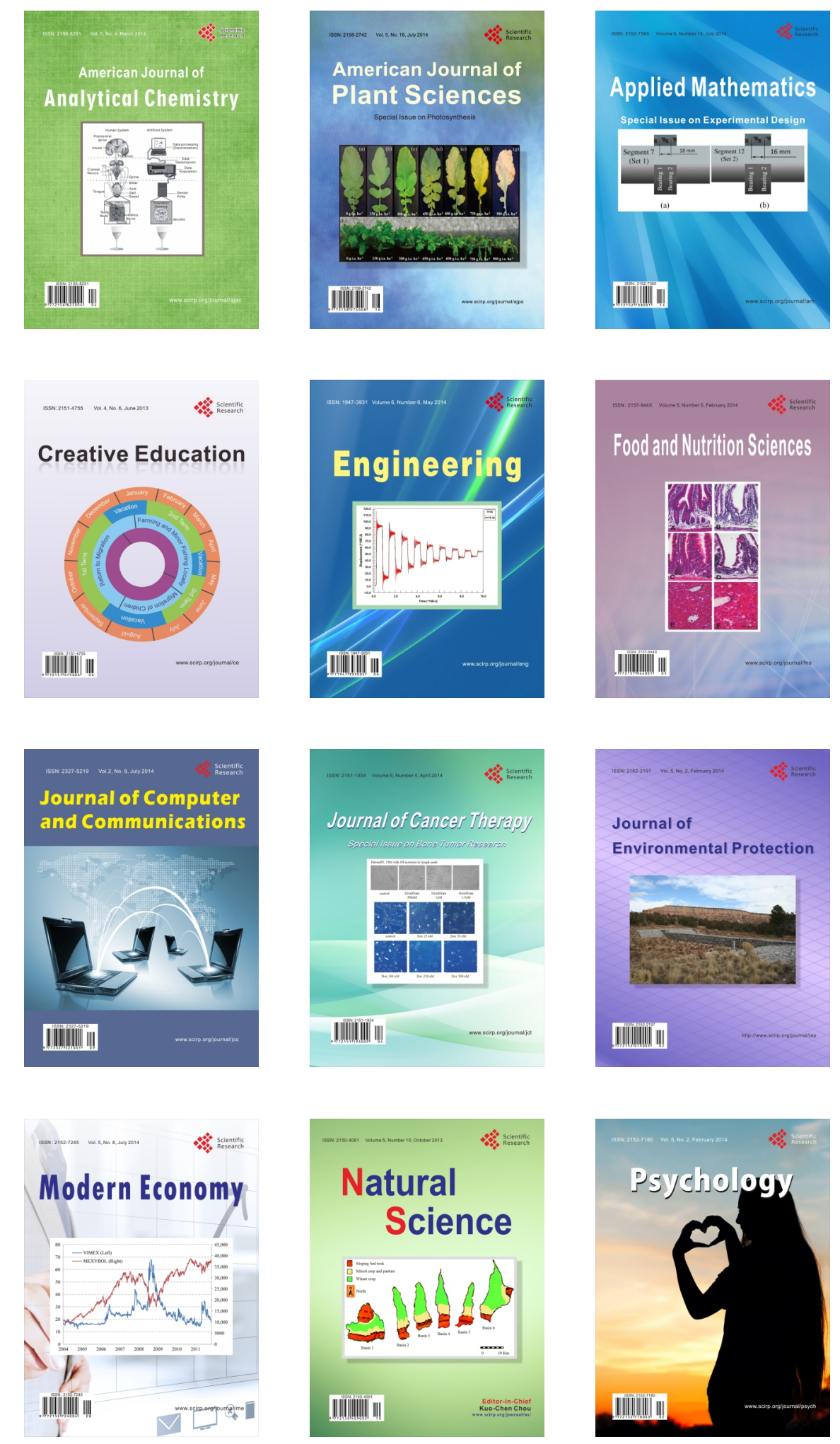